\title{
Smart Textiles and Nano-Technology: A General Overview
}

\author{
Md. Syduzzaman ${ }^{1 *}$, Sarif Ullah Patwary², Kaniz Farhana ${ }^{3}$, Sharif Ahmed ${ }^{4}$ \\ ${ }^{1}$ Department of Textile Management and Business Studies, Bangladesh university of Textiles \\ ${ }^{2}$ Department of Textile Engineering, National Institute of Textile Engineering and Research, Bangladesh \\ ${ }^{3}$ Department of Apparel Manufacturing Engineering, Bangladesh university of Textiles \\ ${ }^{4}$ Department of Yarn Manufacturing Engineering, Bangladesh university of Textiles
}

\begin{abstract}
Smart textiles are fabrics that have been designed and manufactured to include technologies that provide the wearer with increased functionality. These textiles have numerous potential applications, such as the ability to communicate with other devices, conduct energy, transform into other materials and protect the wearer from environmental hazards. Research and development towards wearable textile-based personal systems allowing e.g. health monitoring, protection and safety, and healthy lifestyle gained strong interest during the last few years. Smart fabrics and interactive textiles' activities include personal health management through integration, validation, and use of smart clothing and other networked mobile devices as well as projects targeting the full integration of sensors/ actuators, energy sources, processing and communication within the clothes to enable personal applications such as protection/safety, emergency and healthcare. This writing includes the origin and introduction of smart textile and integrated wearable electronics for sport wear, industrial purpose, automotive and entertainment applications, healthcare \& safety, military, public sectors and new developments in smart textiles.
\end{abstract}

Keywords: Health care and safety; Interactive textiles; Nanotechnology; Sportswear; Smart textiles

\section{Introduction}

SMART TEXTILES are defined as textiles that can sense and react to environmental conditions or stimuli, from mechanical, thermal, magnetic, chemical, electrical, or other sources. They are able to sense and respond to external conditions (stimuli) in a predetermined way. Textile products which can act in a different manner than an average fabric and are mostly able to perform a special function certainly count as smart textiles [1]. Other examples of smart textiles include fabrics capable of releasing medication or moisturizer in to the skin, fabrics that help control the vibration of muscles during athletic activities and materials that regulate body temperature. There are also simpler, aesthetic applications for smart textiles, including those that can change color, light up in patterns or potentially display pictures and video [2].

The original function of textiles was to shield man from cold and rain. Later on in history aesthetic aspects also came to play a role in clothing. Much more recently a new generation of textiles has arisen; smart and interactive textiles. Interactive textiles are a relatively new discipline in the textile sector. They are active materials that have sensing and actuation properties. Their potential is enormous. one could think of smart clothing that makes us feel comfortable at all times, during any activity and in any environmental conditions, a suit that protects and monitors, that warns in case of danger and even helps to treat diseases and injuries. Such clothing could be used from the moment we are born till the end of our life. Some of the more important efforts include applications that Aid in patient health monitoring through sensor embedded garments that track and record biometric data, helps to improve athletic performance both by analyzing sensor data and adapting to changing conditions [3]. So as to improve performance over the time. Provides environmental sensing and communication technologies for military defense and other security personals. Present new structural and decorative solutions for fashion design. The smart textile can sense and react to environmental conditions or stimuli from mechanical, thermal, chemical, electrical, magnetic or other sources. Three components must be present in smart textiles. i.e. sensors, actuators and controlling units [4]. Modified textile material and miniaturized electronic devices create smart cloths. These cloths are like ordinary cloth providing special function in various situations according to the design and application.

\section{History of Smart Textiles Development}

The basic materials needed to construct e-textiles, conductive threads and fabrics have been around for over 1000 years. In particular, artisans have been wrapping fine metal foils, most often gold and silver, around fabric threads for centuries [5]. Many of Queen Elizabeth I's gowns, for example, are embroidered with gold-wrapped threads. (See the entry on Goldwork for more information)

At the end of the $19^{\text {th }}$ century, as people developed and grew accustomed to electric appliances, designers and engineers began to combine electricity with clothing and jewelry-developing a series of illuminated and motorized necklaces, hats, broaches and costumes $[6,7]$. For example, in the late 1800 s, a person could hire young women adorned in light-studded evening gowns from the Electric Girl Lighting Company to provide cocktail party entertainment [8].

In 1968, the Museum of Contemporary Craft in New York City held a groundbreaking exhibition called Body Covering that focused on the relationship between technology and apparel. The show featured astronauts' space suits along with clothing that could inflate and deflate light up, and heat and cool itself [9]. Particularly noteworthy in this collection was the work of Diana Dew, a designer who created a line of electronic fashion, including electroluminescent party dresses and belts that could sound alarm sirens [10].

*Corresponding author: Md. Syduzzaman, Lecturer, Department of Textile Management and Business Studies, Bangladesh University of Textiles, Bangladesh, Tel: +20 122217 4602; E-mail: sayeed33tex@gmail.com

Received December 16, 2014; Accepted January 24, 2015; Published February 15,2015

Citation: Syduzzaman, Patwary SU, Farhana K, Ahmed S (2015) Smart Textiles and Nano-Technology: A General Overview. J Textile Sci Eng 5: 181. doi:10.4172/2165-8064.1000181

Copyright: (c) 2015 Syduzzaman, et al. This is an open-access article distributed under the terms of the Creative Commons Attribution License, which permits unrestricted use, distribution, and reproduction in any medium, provided the original author and source are credited. 
In 1985, an inventor by the name of Harry Wainwright (www. hleewainwright.com) created the first fully animated sweatshirt consisting of fiber optics, leds, and a microprocessor to control individual frames of animation resulting in a full color cartoon on the surface of apparel. Wainwright went on to invent the first machine in 1995 enabling fiber optics to be machined into fabrics, the process needed for manufacturing enough for mass markets and hired a German machine designer, Herbert Selbach, from Selbach Machinery to produce the world's first CNC machine able to automatically implant fiber optics into any flexible material (www.usneedle.com) in 1997. Receiving the first of a dozen patents based on LED/Optic displays and machinery in 1989, the first CNC machines went into production in 1998 beginning with the production of animated coats for Disney Parks in 1998. The first ECG Bio-Physical display jackets employing LED/Optic displays were created by Wainwright and David Bychkov, the CEO of Exmovere at the time in 2005 using GSR sensors in a watch connected via Bluetooth to the embedded machine washable display in a denim jacket and were demonstrated at the Smart Fabrics Conference held in Washington D.C. May 7th, 2007. Additional Smart Fabric technologies were unveiled by Wainwright at two Flextech Flexible Display conferences held in Phoenix, AZ, showing Infra-Red digital displays machine embedded into fabrics for IFF (Identification of Friend or Foe) which were submitted to BAE Systems for evaluation in 2006 and won an "Honorable Mention" award from NASA in 2010 on their Tech Briefs, "Design the Future" contest. MIT personnel purchased several fully animated coats for their researchers to wear at their demonstrations in 1999 to bring attention to their "Wearable Computer" research. Wainwright was commissioned to speak at the Textile and Colorists Conference in Melbourne, Australia on June 5th, 2012 where he was requested to demonstrate his fabric creations that change color using any smart phone, indicate callers on mobile phones without a digital display, and contain WIFI security features that protect purses and personal items from theft.

In the mid 1990s a team of MIT researchers led by Steve Mann, Thad Starner, and Sandy Pentland began to develop what they termed wearable computers. These devices consisted of traditional computer hardware attached to and carried on the body. In response to technical, social, and design challenges faced by these researchers, another group at MIT, that included Maggie Orth and Rehmi Post, began to explore how such devices might be more gracefully integrated into clothing and other soft substrates. Among other developments, this team explored integrating digital electronics with conductive fabrics and developed a method for embroidering electronic circuits $[11,12]$.

\section{Classification of Smart Textiles}

\section{Passive smart textiles}

The first generations of smart textiles, which provide additional feature in a passive mode i.e. irrespective of the change in the environment [13]. For example, a highly insulating coat would remain insulating to the same degree irrespective of the outside temperature. Wide range of capabilities, including anti-microbial, antiodour, anti-static, bullet proof are the other examples.

\section{Active smart textiles}

The second generation has both actuators and sensors. Textiles which adapt their functionality to changing environment automatically are active smart textiles. Active smart textiles are shape memory, chameleonic, water-resistant and vapor permeable (hydrophilic/ nonporous), heat storage, thermo regulated, vapor absorbing, and heat evolving fabric and electrically heated suits.

\section{Ultra smart textiles}

Very smart textiles are the third generation of smart textiles, which can sense, react and adopt themselves to environmental conditions or stimuli. A very smart or intelligent textile essentially consists of a unit, which works like the brain, with cognition, reasoning and activating capacities. The production of very smart textiles is now a reality after a successful marriage of traditional textiles and clothing technology with other branches of science like material science, structural mechanics, sensor and actuator technology, advance processing technology, communication, artificial intelligence, biology etc.

New fibre and textile materials, and miniaturized electronic components make the preparation of smart textiles possible, in order to create truly usable smart clothes. These intelligent clothes are worn like ordinary clothing, providing help in various situations according to the designed applications.

\section{Smart Materials and Fibers in Smart Textiles}

'Smart' or 'Functional' materials usually form part of a 'Smart System' that has the capability to sense its environment and the effects thereof and, if truly smart, to respond to that external stimulus via an active control mechanism. Smart materials and systems occupy a 'Technology space', which also includes the areas of sensors and actuators [14].

\section{Materials}

The materials of our surroundings are being "intellectualized". These materials can interact, communicate and sense. Polymeric or carbon coated threads Conductive yarn, conductive rubber, and conductive ink have been developed into sensors or used as an interconnection substrate. Conductive yarns and fibers are made by mixing pure metallic or natural fibers with conductive materials. Pure metallic yarns can be made of composite stainless steel or fine continuous conductive metal-alloy combination of fibers with conductive materials can be completed by the methods namely: Fibers filled with conductive material (e.g., carbon -or metallic particles); Fibers coated with conductive polymers or metal and Fibers spun with thin metallic or plastic conductive threads.

Metallic silk, organza, stainless steel filament, metal clad aramid fiber, conductive polymer fiber, conductive polymer coating and special carbon fiber have been applied to the manufacture of fabric sensors.

Materials such as metallic, optical fibers and conductive polymers may be integrated into the textile structure, thus supplying electrical conductivity, sensing capabilities and data transmission. Organic polymers may provide a solution to overcome the stiffness of inorganic crystals such as silicon. These materials are light, elastic, resilient, mechanically flexible, inexpensive and easy to process.

\section{Metal fibers}

Metal threads are made up of metal fibers which are very thin metal. The fibers are produced either through a bundle-drawing process or else shaved off the edge of thin metal sheeting. Metallic threads and yarns may be knitted or woven into a textile and used to form interconnects between components (Figure 1). They may also be used as electrodes for monitoring electrical physiological activity such as electrocardiogram (ECG) signals.

\section{Conductive inks}

A layout can be screen-printed using conductive inks to add 
Citation: Syduzzaman, Patwary SU, Farhanaz K, Ahmed S (2015) Smart Textiles and Nano-Technology: A General Overview. J Textile Sci Eng 5: 181. doi: $10.4172 / 2165-8064.1000181$

Page 3 of 7

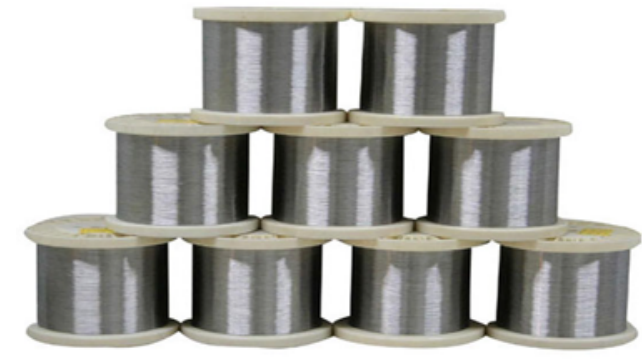

Figure 1: Metal fiber.

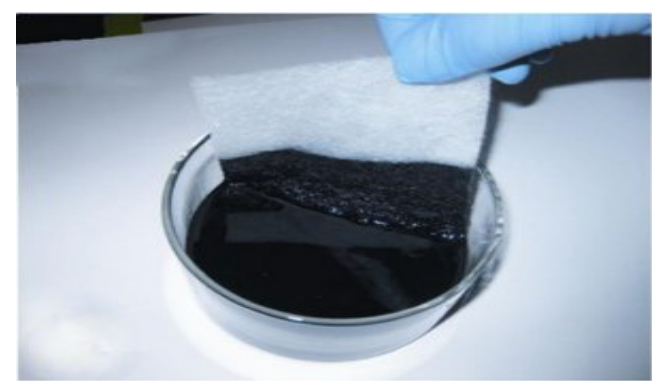

Figure 2: Conductive Inks.

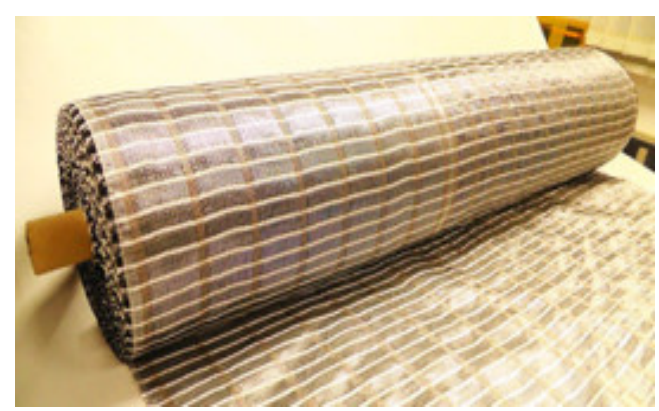

Figure 3: Electrically conductive textiles.

conductivity to specific areas of a garment. Carbon, copper, silver, nickel and gold may be added to conventional printing inks to make them conductive (Figure 2). Printed areas can be subsequently used as switches or pressure pads for the activation of circuits.

\section{Inherently conductive polymers}

Inherently conductive polymers have both sensing and actuation properties. Some commonly had known ICPs include polyacetylene, polypyrrole, polyaniline. Polypyrrole (PPy) is most suitable as it has high mechanical strength with high elasticity, is relatively stable in air and electro. The major advantage of this approach is that the sensors retain the natural texture of the material. The problem with these devices is a variation in resistance over time and high response time.

\section{Electrically conductive textiles}

Electrically conductive textiles are already used for years in various industrial application fields for the purpose of controlling static and electromagnetic interference shielding. Nowadays, textiles are modified to offer a good electrical conductivity to be applied in smart textiles (Figure 3 ). Here electrically conductive textiles are used as electrodes or as interconnection between the different components.

\section{Optical fibers}

Plastic optical fibers may be easily integrated into a textile. They have the advantage of not generating heat and are insensitive to EM radiation. Optical fibers may serve a number of functions in a smart garment-transmit data signals, transmit light for optical sensing, detect deformations in fabrics due to stress and strain and perform chemical sensing. Commercially available Luminex ${ }^{\circ}$ fabric is a textile with woven optical fibers capable of emitting its own light (Figure 4). While this has aesthetic appeal for the fashion industry it is also used in safety vests and potential to be used for data transmission.

\section{Coating with nano-particles}

Coating a fabric with nano particles is being widely applied within the textile industry to improve the performance and functionality of textiles. Nanotechnology can add permanent effects and provide high durability fabrics. Coating with Nano-particles can enhance the textiles with properties such as anti-bacterial, water-repellence, UV-protection and self-cleaning, while still maintaining breath-ability and tactile properties of the textile. Nano-tex has a range of products using such coatings to resist spills, repel and release stains, and resist static.

\section{Shape memory materials}

Shape memory alloys, such as nickel-titanium, have been developed to provide increased protection against sources of heat. A shape memory alloy possesses different properties below and above the temperature at which it is activated. At the activation temperature, the alloy exerts a force to return to a previously adopted shape and becomes much stiffer. The temperature of activation can be chosen by altering the ratio of nickel to titanium in the alloy (Figure 5).

Cuprous-zinc alloys are capable of producing the reversible variation needed for protection from changeable weather conditions. Shape Memory Polymers have the same effect as the Ni-Ti alloys but, being polymers, they will potentially be more compatible with textiles. Electro active polymers EAPs are generally made up of high

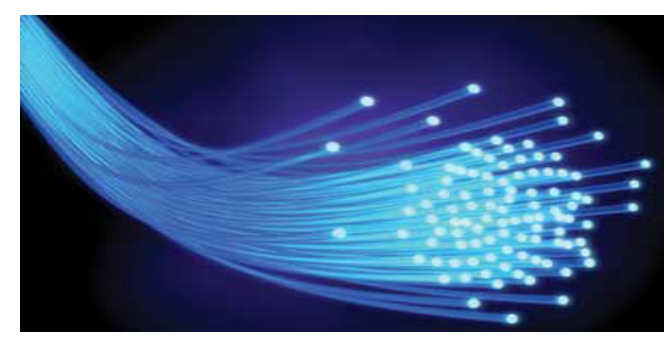

Figure 4: Optical fibers.

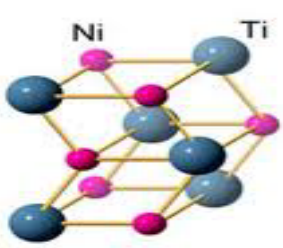

Martensite

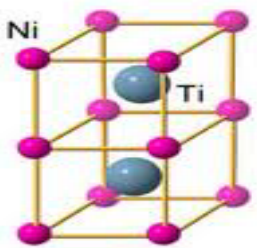

Austenite
Figure 5: Shape memory materials. 
functionalized polymer. One of the most famous EAPs is the "Gel robots" made up of poly 2-acrylamido-2-methylpropane sulfonic acid that is fully researched for applications in the replacement of muscles and tendons.

\section{Chromic materials}

Chromic materials can change their color according to external conditions. These materials have mostly used in fashion, to create funny color changing designs [15]. According to the stimuli type, chromic materials can be categorized as-

Photo chromic: External stimulus is light.

Thermo chromic: External stimulus is heat.

Electro chromic: External stimulus is electricity.

Piezoro chromic: External stimulus is pressure.

Solvate chromic: External stimulus is liquid or gas.

\section{Phase change materials}

Now days, phase change materials are highly applied in the field of textiles for different kinds of products such as apparel, underwear, socks, shoes, bedding accessories and sleeping bags. For multifunctional products also are applicable in the specialty items like anti ballistic vests, automotive, medical or for other industrial applications.

Application of PCMs in textiles: For a Suitable application of PCMs in textiles the temperature must be within a temperature range of human skin. This exciting property of PCMs would be useful for the application of producing protective garments in all- kinds of weathers from the strongest winter to the hottest summer. Textile materials treated with PCMs can store the heat if it is excess and release it back when the heat is needed. The PCMs can be applied either in the fibre spinning or during chemical finishing processes like Coating, lamination and others.

\section{Incorporating Smartness into Apparels}

The key steps in the integration of electronic devices with apparel during the manufacturing process interface can be seen in Figure 6 . If the sensors and micro processors are integrated into the yarn itself they will not interfere with the normal manufacturing process of the garment. The technology is based on the encapsulated area. The vision is the development of novel technology for fabricating electronically active and sensor fibers.

In the future a shirt could monitor your ECG, be your iPod, and talk to you! It is possible to incorporate electronic chips, optical and thermal devices, into yarn (Figure 6). Yarns were created with LEDs in them so that the functionality could be easily demonstrated. Hitachi is the first company to produce a chip small enough to be embedded with

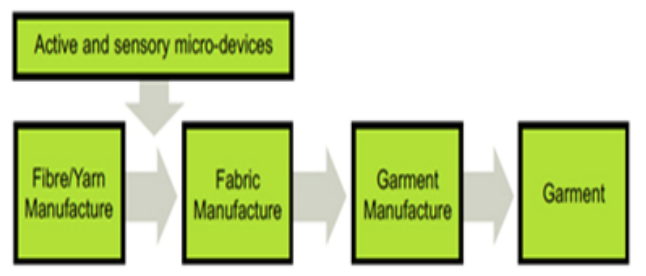

Figure 6: Steps to incorporating smartness in apparel. textile fibers, called the Mu-chip. It is $0.4 \mathrm{~mm} \times 0.4 \mathrm{~mm} \times 0.15 \mathrm{~mm}$. Work is now being carried out on light emitting yarns, ones that will measure stresses and strains on fabrics and that will sense fluids and liquids. The fabric of the future won't be just plain chiffon, silk or cotton. Instead electroluminescent material, microprocessors and LEDs may be woven together with clothing fibers to create smart textiles.

\section{How Does a Smart Textile Work?}

Smart textiles can be made by incorporating smart materials, conductive polymers, encapsulated phase change materials, shape memory polymers and materials and other electronic sensors and communication equipments. These materials interact - according to their designed feature with the stimuli in their environment. All smart materials involve an energy transfer from the stimuli to response given out by the material. They are integrated and complex materials. They have the ability do some sort of processing, analyzing and responding. Even they can adapt to the environment. They got full ability to change themselves depending on - temperature, pressure, density, or internal energy-change [16]. The amount of energy transferred to make this change is determined by the properties of the material. This relationship between the amount of energy required and the degree of the specific change governs the behaviour of all materials, including smart ones. If they get energy or any stimuli from the outer environment they do not do any change on it .They just resist it or absorb it. For example, a material's specific heat (property) will determine how much heat (energy) is needed in order to change its temperature by a specified amount

\section{Incorporating Smartness into Textiles}

Textile to behave smartly it must have a sensor, an actuator (for active smart textiles) and a controlling unit (for very smart textiles). These components may be fiber optics, phase change materials, shape memory materials, thermo chromic dyes, miniaturized electronic items etc. These components form an integrated part of the textile structure and can be incorporated into the substrate at any of the level namely: fiber spinning level; yarn/fabric formation level; finishing level. The active (smart) material can be incorporated into the spinning dope or polymer chips prior to spinning e.g. lyocell fiber can be modified by admixtures of electrically conductive components during production to make an electrically conductive cellulosic fiber. Sensors and activators can also be embedded into the textile structure during fabric formation e.g. during weaving. Many active finishes have been developed which are imparted to the fabric during finishing. The electronic control units can be synchronized with each other during finishing. Techniques such as microencapsulation are generally preferred for incorporation of smartness imparting material in the textile substrate.

\section{Application of Smart Textiles}

\section{Health}

The development of wearable monitoring systems is already having an effect on healthcare in the form of "Telemedicine". Wearable devices allow physiological signals to be continuously monitored during normal daily activities [17]. This can overcome the problem of infrequent clinical visits that can only provide a brief window into the physiological status of the patient. Representative examples are e.g.: Wireless-enabled garment with embedded textile sensors for simultaneous acquisition and continuous Monitoring of ECG, respiration, EMG, and physical activity. The "smart cloth" embeds a strain fabric sensor based on piezo resistive yarns and fabric electrodes 
realized with metal based yarns. -Sensitized vest including fully woven textile sensors for ECG and respiratory frequency detection and a Portable electronic board for motion assessment, signal pre-processing, and bluetooth connection for data transmission. Wearable sensitized garment that measures human heart rhythm and respiration using a three lead ECG shirt. The conductive fibre grid and sensors are fully integrated (knitted) in the garment (Smart Shirt) (Figure 7).

\section{Life belt}

Life belt is a trans-abdominal wearable device for long-term health monitoring that facilitates the parental monitoring procedures for both the mother and the fetus. This life belt is very useful in case of pregnant women. Pregnant women living in remote areas work during pregnancy and face certain health problems (e.g. high blood pressure, kinetic problems requiring immobilization, kidney or heart diseases, multiple pregnancies). Life belt is a support tool for the obstetrician, who is enabled to monitor patients remotely, evaluate automated preliminary diagnosis of their condition based on collected and analyzed vital signs, access patients' medical data at any time and most importantly be alerted.

\section{Life jacket}

Life jacket is a medical device worn by the patient that consequently reads their blood pressure or monitors the heart rate; the information is transferred to a computer and read by medical staff. A specialized camera in the form of headwear has been developed to be worn by paramedics. Visual information captured by the camera can be transferred directly to medical staff at the hospital enabling them to advise instantly on appropriate treatment. Cuff-less BP can be measured from the radial pulse waveform by arterial tonometry by using this life jacket.

\section{Military/defense}

Around the world military forces are exploring how smart clothing can be used to increase the safety and effectiveness of military forces. In extreme environmental conditions and hazardous situations there is a need for real time information technology to increase the protection and survivability of the people working in those conditions. Improvements in performance and additional capabilities would be of immense assistance within professions such as the defense forces and emergency response services. The requirements for such situations are to monitor vital signs and ease injuries while also monitoring environment hazards such as toxic gases (Figure 8). Wireless communication to a central unit allows medics to conduct remote triage of casualties to help them respond more rapidly and safely [18].

\section{Fashion and entertainment}

As the technology is becoming more flexible various electronic

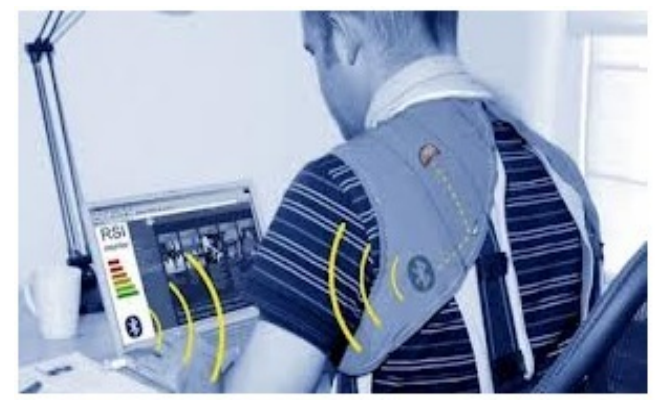

Figure 7: Wearable devices in health.

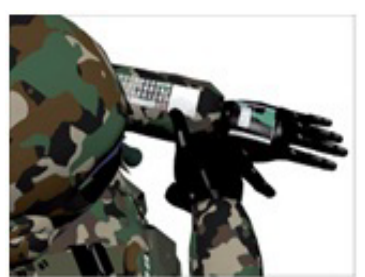

Figure 8: Smart textiles in Military/Defense

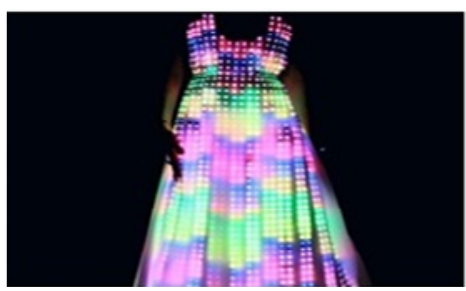

Figure 9: Light emitting smart textiles.

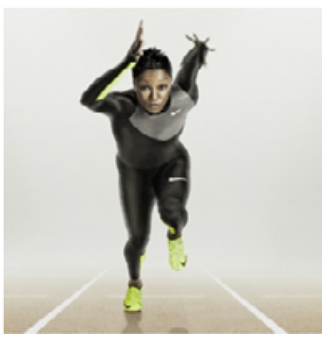

Figure 10: Smart sportswear.

devices and components clothes becoming truly portable devices. Already there are textile switches integrated into clothing for the control of such devices. While technology may be hidden through invisible coatings and advanced fibers, it can also be used to dramatically change the appearance of the textile, giving new and dazzling effects (Figure 9). Light emitting textiles are finding their way onto the haute couture catwalks, suggesting a future trend in technical garments.

\section{Sportswear}

Sports are area of important smart clothing developments. In general a number of important functions can be implemented using smart devices or clothing (Figure 10). These include: Monitoring heart rate, breathing, body temperature and other physiological parameters; Measuring activity, for example determining the number of steps taken, the total distance travelled; Acting to actively stimulate muscles e.g. using electrical muscle stimulation; Work against activity to provide 'smart' resistance training; Record aspects of performance, such a foot pressure or specific joint movements; Protect against injury.

\section{Smart sports shoe}

Global Positioning Systems (GPS) incorporated into walking shoes which allow the user to be tracked by mountain rescues services. They can also used to monitor the where about of young children. Gloves that contain heaters, or built in LED's emitting light so that a cyclist can be seen in the dark.

\section{The sensory baby vest}

The sensory baby vest is equipped with sensors that enable the 


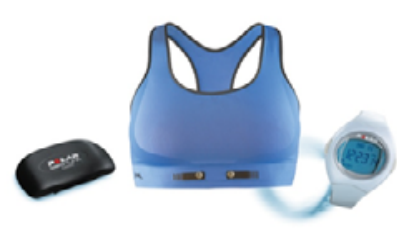

Figure 11: Smart Bra.

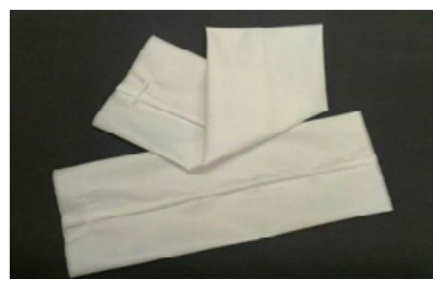

Figure 12: Ultrasonic bonding.

constant monitoring of vital functions such as heart, lungs, skin and body temperature which can be used in the early detection and monitoring of heart and circulatory illness. It is hoped to use this vest to prevent cot death and other life-threatening situations in babies. The sensors are attached in a way that they do not pinch or disturb the baby when it is sleeping.

\section{The smart bra}

One of the best examples for improving comfort is an Australian invention: the Smart Bra. They have developed a bra that will change its properties in response to breast movement. This bra will provide better support to active women when they are in action. The Smart Bra will tighten and loosen its straps, or stiffen and relax its cups to restrict breast motion, preventing breast pain and sag (Figure 11). The conductive polymer coated fabrics will be used in the manufacture of the Smart Bra. The fabrics can alter their elasticity in response to information about how much strain they are under. The Smart Bra will be capable of instantly tightening and loosening its straps or stiffening cups at excessive movement.

\section{Latest Development in Smart Textiles and Nano- Technology}

\section{Ultrasonic assembly}

Ultrasonic bonding occurs when high frequency electrical energyconverted to acoustical, mechanical vibrations and channeled through a horn-creates a rapid heat build up at the material contact point, causing the fabric between the horn and anvil-or the rotating pattern wheel in the case of the Seam Master-to soften and fuse (Figure 12). According to the company, in one pass, the machine seals and trims without thread, glue or other consumables, as much as four times faster than conventional sewing machines and ten times faster than adhesive methods. The Seam Master is also said to be easy to operate with minimal training required.

\section{Life on earth}

"Radiation is a danger faced by the military, health care workers, and the first-responder in many different scenarios. Our anatomically correct applications addressing protection as well as comfort, will reach the people who need it much faster as extreme career wear, in military, medical, energy, transportation, safety, protection and first responders.

\section{Life on mars}

Fab-designs President and textile engineer, Connie Huffa presents several soft and stretchable 3-dimensional fabric swatches with different textured sides that she calls a spacer. A spacer is a fabric with two face sides and a yarn constructed hollow gap between the faces (Figure 13).

"The initial focus for our fabrication efforts is to meet NASA's challenge of a potential space mission to Mars, since astronauts are exposed to many different situations that have the potential to cause irreversible harm to the body. This extremely hostile environment requires a sophisticated fabrication that will protect the wearer from hazards emanating from outer space, the space craft itself, and health problems from the human body's reaction to antigravity conditions," she says.

\section{Fiber in space elevator challenge}

A space elevator is a proposed type of space transportation system, whose main component is a ribbon-like cable (also called a tether) anchored to the surface and extending into space. It is designed to permit vehicle transport along the cable from a planetary surface, such as the Earth's, directly into space or orbit, without the use of large rockets by mechanical means to orbit, and descended to return to the surface from orbit. Battery-powered robots, called climbers, made by participating teams will race up and down the Technora belt and rope to see which can travel the fastest and farthest.

\section{Innovative sportswear}

New product developments in sportswear not only make garments look and fit better, they also help athletes perform better. Many of these require uses of new or specialist technology within the manufacture of the garments, not just the materials they were made from. The market leaders present these specialist technologies at Reprocess.

Smart textiles are an example. The Adidas miCoach Elite System has been introduced to football to help with coaching and game monitoring. For the Olympics, Speedo introduced its Fastskin Racing System which combines the swimsuit, cap and goggles into a unified system, which Speedo claim enhances both comfort and hydrodynamic efficiency. Three-dimensional CAD software is used to help develop the design for sportswear (Figure 14). It is used to create custom fit models, build life-like digital clothing samples, and adjust these based on virtual fit [19].

\section{Prospect of Smart Textiles}

Rising demand for smart and interactive textiles from the transportation industry is likely to be one of the major factors for the growth of the market. Furthermore, growth in medical and healthcare industries is anticipated to lead to higher demand for smart textiles

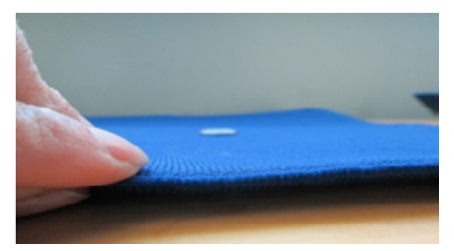

Figure 13: 3-dimensional fabric swatches. 
Citation: Syduzzaman, Patwary SU, Farhanaz K, Ahmed S (2015) Smart Textiles and Nano-Technology: A General Overview. J Textile Sci Eng 5: 181. doi:10.4172/2165-8064.1000181

Page 7 of 7

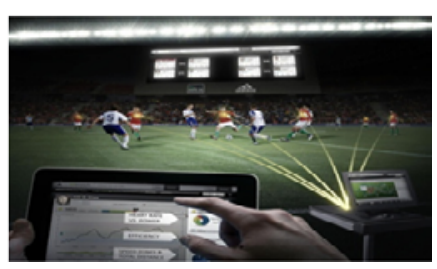

Figure 14: Innovative Sportswear.

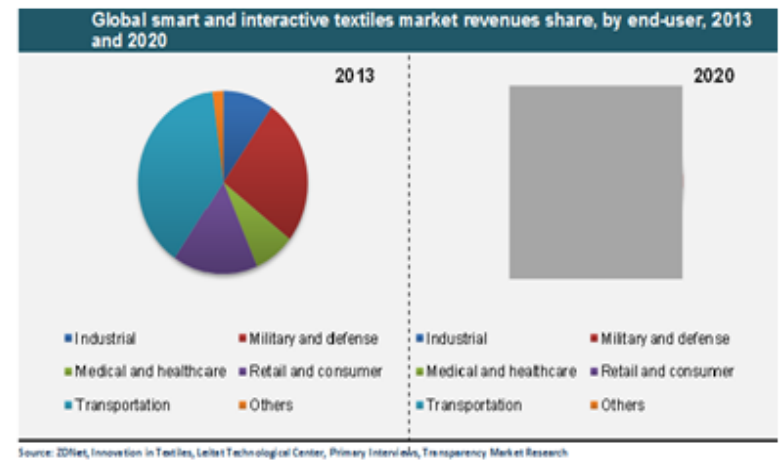

Figure 15: Innovative Sportswear.

during the forecast period. However, market growth is likely to be sluggish due to high prices of finished products of smart textiles as compared to conventional textiles. Rising number of research and development activities for product and technological innovation is expected to provide new opportunities for market growth.

With over $38 \%$ share, the transportation segment accounted for the largest demand for smart textiles in 2013. New applications such as measuring heart rate, heating of seats, smart seat belts and functioning of steering wheels hold immense potential in the automotive industry. The industrial application segment is anticipated to lead the market in the near future (Figure 15). It is projected to grow at a CAGR of $17.3 \%$ between 2014 and 2020 due to a rise in the number of industrial activities such as logistics and supply chain management in emerging regions such as Asia Pacific. Other prominent applications of smart textiles in industrial applications include various protection devices such as personal protective equipment, which is significantly used in industrial plants, manufacturing facilities, etc. Extensive research and development has resulted in commercialization of smart textiles for fire fighters; however, a gap still exists between commercialization and prototype development.

\section{Conclusions}

Previously smart textiles were presented as imaginary products and used in very limited areas. After scientific efforts and development phases, nowadays smart textiles are an implanted customer interest and are presented as the future of the textile industry. Now many commercial products are available and, as it have been presented in this article. A lot of scientists are developing new solutions, ideas and concrete products with the emerging demand of smart textiles in various phases of life. The global markets of smart textiles are expected to reach USD 1500 million according to new study of Grant View Research, Inc.

\section{References}

1. http://www.fibre2fashion.com/industry-article/4/335/smart-textile3.asp

2. http://www.ask.com/beauty-fashion/smart-textiles-d7ff8fb58a817a26

3. Shin Y, Yoo DI, Son K (2005) Development of thermoregulating textile materials with microencapsulated phase change materials (PCM). II. Preparation and application of PCM microcapsules. J Appl Polym Science 96: 2005-2010.

4. Bendkowska W, Tysiak J, Grabowski L (2005) Determining temperature regulating factor for apparel fabrics containing phase change material. Int $J$ Clothing Science and Technology 17: 209-214.

5. Marvin C (1990) When Old Technologies Were New: Thinking About Electric Communication in the Late Nineteenth Century. Oxford University Press, USA.

6. Gere C, Rudoe J (2010)] Jewellery in the Age of Queen Victoria: A Mirror to the World.

7. http://query.nytimes.com/gst/abstract.html?res=FA0912FB3A5C15738DDDAF 0A94DC405B8484F0D3

8. Smith $\mathrm{P}$ (1968) Body Covering. Museum of Contemporary Crafts, the American Craft Council, New York.

9. http://www.thecreatorsproject.com/blog/the-original-creators-diana-dew

10. Post R, Orth M, Russo P, Gershenfeld N (2000) E-broidery: design and fabrication of textile-based computing. IBM Systems Journal 39: 840-860.

11. Electrically active textiles and articles made therefrom.

12. Gregory RV, Samuel RJ, Hanks T (2001) National Textile Centre Annual Report, USA.

13. Oakes J, Batchelor SN, Dixon S (2005) New method for obtaining proper initia clusters to perform FCM algorithm for colour image clustering. Coloration Technology 12: 237-244.

14. Krasovitskii BM, Bolotin BM (2002) Organic Luminescent Materials, Weinheim NY.

15. http://www.innovationintextiles.com/smart-textiles-nanotechnology/nanofrontused-in-bicycle-and-motorcycle-gloves/\#sthash.eG8cQmbM.dpuf

16. http://www.innovationintextiles.com/smart-textiles-nanotechnology/anaselects-performance-polyesters-for-inflight-comfort/\#sthash.82x57GjJ.dpuf

17. http://textilelearner.blogspot.com/2013/04/applications-of-smart-andinteractive.html

18. http://www.stitchprint.eu/news/new-technologies-for-innovative-sportswear/

19. http://www.transparencymarketresearch.com/pressrelease/smart-fabrics-andinteractive-textiles-market.htm 